Article

\title{
Screening a Strain of Aspergillus niger and Optimization of Fermentation Conditions for Degradation of Aflatoxin $B_{1}^{\dagger}$
}

\author{
Wei Zhang, Beibei Xue, Mengmeng Li, Yang Mu, Zhihui Chen, Jianping Li * and Anshan Shan * \\ Institute of Animal Nutrition, Northeast Agricultural University, Harbin 150030, China; \\ E-Mails: dianjini2012@163.com (W.Z.); shanshimen@163.com (B.X.); \\ sjzlimengmeng@163.com (M.L.); muyangmyqq@163.com (Y.M.); chenzh1980@163.com (Z.C.) \\ $\dagger$ Some data of the manuscript has been published in the conference paper: \\ Xue, B.B.; Shan, A.S.; Shi, B.M. Screening and identification of an aflatoxin B1-degradation strain \\ from moldy cereals. Adv. Mater. Res. 2013, 610-613, 3461-3465. \\ In Proceedings of the 2nd International Conference on Energy, Environment and \\ Sustainable Development, EESD 2012, Jilin, China, 12-14 October 2012. \\ * Authors to whom correspondence should be addressed; \\ E-Mails: ljpneau@163.com (J.L.); asshan@neau.edu.cn (A.S.); \\ Tel.: +86-451-5519-1439 (J.L.); +86-451-5519-0685 (A.S.); \\ Fax: +86-451-5510-3336 (J.L. \& A.S.).
}

External Editor: Annie Pfohl-Leszkowicz

Received: 13 September 2014; in revised form: 23 October 2014 / Accepted: 5 November 2014 / Published: 13 November 2014

\begin{abstract}
Aflatoxin $\mathrm{B}_{1}$, a type of highly toxic mycotoxin produced by some species belonging to the Aspergillus genus, such as Aspergillus flavus and Aspergillus parasiticus, is widely distributed in feed matrices. Here, coumarin was used as the sole carbon source to screen microorganism strains that were isolated from types of feed ingredients. Only one isolate (ND-1) was able to degrade aflatoxin $\mathrm{B}_{1}$ after screening. ND-1 isolate, identified as a strain of Aspergillus niger using phylogenetic analysis on the basis of $18 \mathrm{~S}$ rDNA, could remove $26.3 \%$ of aflatoxin $\mathrm{B}_{1}$ after $48 \mathrm{~h}$ of fermentation in nutrient broth (NB). Optimization of fermentation conditions for aflatoxin $\mathrm{B}_{1}$ degradation by selected Aspergillus niger was also performed. These results showed that $58.2 \%$ of aflatoxin $\mathrm{B}_{1}$ was degraded after $24 \mathrm{~h}$ of culture under the optimal fermentation conditions. The aflatoxin $\mathrm{B}_{1}$ degradation activity of Aspergillus niger supernatant was significantly stronger than cells
\end{abstract}


and cell extracts. Furthermore, effects of temperature, heat treatment, $\mathrm{pH}$, and metal ions on aflatoxin $\mathrm{B}_{1}$ degradation by the supernatant were examined. Results indicated that aflatoxin $\mathrm{B}_{1}$ degradation of Aspergillus niger is enzymatic and this process occurs in the extracellular environment.

Keywords: Aspergillus niger; coumarin; aflatoxin $\mathrm{B}_{1}$; degradation

\section{Introduction}

With the growing frequency of food and feed safety issues, there has been an increased focus, specifically, on bio-pollution problems, in which fungal toxins are one of the main factors causing food and feed contamination. Aflatoxins are a group of highly toxic secondary metabolites primarily produced by Aspergillus flavus and Aspergillus parasiticus [1,2]. Other Aspergillus species producing aflatoxin are A. pseudotamarii [3], A. bombycis [4], and A. nomius [5]. Similar to many microbial secondary metabolites, aflatoxins consist of a family of closely related compounds, which include aflatoxin $\mathrm{B}_{1}, \mathrm{~B}_{2}, \mathrm{G}_{1}, \mathrm{G}_{2}, \mathrm{M}_{1}$, and $\mathrm{M}_{2}$. Aflatoxins, particularly aflatoxin $\mathrm{B}_{1}$, demonstrate carcinogenic, teratogenic, hepatotoxic, and immunosuppressive effects on human and animals [6,7].

On the basis of the severe hypertoxicity and wide distribution demonstrated by aflatoxin $\mathrm{B}_{1}$, many physical and chemical methods have been applied to inactivate and detoxify this compound in feed systems $[8,9]$. However, most physical and chemical detoxification methods have their own limitations, such as a loss of the product organoleptic qualities and feed nutritional value, unknown health effects, and the high cost of specific equipment [10]. It has been reported that bacteria and fungi can contribute to the reduction of aflatoxins via biological degradation [11,12]. Moreover, bacteria have been used more often due to advantages such as enhanced degradation within a shorter time period, as well as the production of non-pigments [13]. Several previous reports have described the degradation of aflatoxin $\mathrm{B}_{1}$ by many different microorganisms. Farzaneh et al. [14] found that Bacillus subtilis UTBSP1 could significantly remediate aflatoxin $\mathrm{B}_{1}$ in nutrient broth culture and pistachio nuts by $85.66 \%$ and 95\%, respectively. Many lactic acid bacteria (LAB), such as Propionibacterium, Lactococcus, Bifidobacterium, and Lactobacillus, were able to remove aflatoxin $\mathrm{B}_{1}$, via a proposed adhesion method [15]. In addition, several other microorganisms, such as Armillariella tabescens [16], Mycobacterium fluoranthenivorans [17], Rhodococcus erythropolis [18], Stenotrophomonas maltophilia [19], and Pseudomonas putida [20] were reported to degrade aflatoxin $\mathrm{B}_{1}$.

The objective of this study was to seek out alatoxin $\mathrm{B}_{1}$ degradation microorganisms isolated from microorganism populations of different feed ingredients, to optimize the fermentation conditions and explore the factors affecting degradation efficiency.

\section{Results and Discussion}

\subsection{Isolation of Microorganisms}

Approximately 100 strains were isolated from the vast microbial populations in the feedstuff samples. But only two strains were obtained after screening by using coumarin medium (CM). Coumarin is the 
basic molecular structure of aflatoxin $\mathrm{B}_{1}$. Thus, microorganisms that could utilize coumarin as a carbon source might also be able to use aflatoxin $\mathrm{B}_{1}$. The metabolizing processes should result in degradation of the aflatoxin $B_{1}$ [19]. Compared with aflatoxin $B_{1}$, it is much safer for users and cheaper to buy. The coumarin method provided an inexpensive, feasible, and effective tool for selecting aflatoxin $\mathrm{B}_{1}$ degradation microorganisms. CM was used in this study for microbial selection. Isolate ND-1 and ND-2 were inoculated onto aflatoxin $\mathrm{B}_{1}$-containing nutrient agar (NA) to estimate its ability to remove aflatoxin $\mathrm{B}_{1}$. The typical blue fluorescent color disappeared around isolate ND-1 under UV light irradiation after $24 \mathrm{~h}$ of incubation. However, for isolate ND-2, the fluorescent color still remained. It indicated that ND-1 could degrade aflatoxin $\mathrm{B}_{1}$ and ND-2 could not. This might be due to the ability of ND-2 to utilize glucose in NA as a carbon source rather than aflatoxin $\mathrm{B}_{1}$.

\subsection{Determination of Aflatoxin $B_{1}$ Degradation}

After incubation times of $12,24,36$, and $48 \mathrm{~h}$, the concentration of aflatoxin $\mathrm{B}_{1}$ residue in the culture was detected. The degradation process of aflatoxin $\mathrm{B}_{1}$ by ND-1 was relatively slow and continuous, with $18.08 \%$ of aflatoxin $\mathrm{B}_{1}$ removed in the first $12 \mathrm{~h}, 21.1 \%$ removed after $24 \mathrm{~h}, 24.4 \%$ removed after $36 \mathrm{~h}$, and $26.3 \%$ removed after $48 \mathrm{~h}$ (Figure 1). Alberts et al. reported that a significant $(p<0.05)$ reduction in aflatoxin $\mathrm{B}_{1}$ was already observed after $2 \mathrm{~h}$ in the presence of Rhodococcus erythropolis extracellular extracts with only $33.2 \%$ residual aflatoxin $\mathrm{B}_{1}$ after $72 \mathrm{~h}$ [18]. Farzaneh et al. found that Bacillus subtilis UTBSP1 could significantly remediate aflatoxin $\mathrm{B}_{1}$ in nutrient broth culture by $85.66 \%$ [14]. Hormisch et al. found that the aflatoxin $\mathrm{B}_{1}$ concentration was reduced to amounts of $70 \%$ to $80 \%$ of the initial concentration within $36 \mathrm{~h}$ by Mycobacterium fluoranthenivorans [17]. For ND-1, the percentage of aflatoxin $\mathrm{B}_{1}$ degradation was much lower compared to other previously reported strains, which might be due to the difference of strains and the lack of optimization of fermentation conditions.

Figure 1. Detrmination of aflatoxin $\mathrm{B}_{1}$ degradation by isolate ND-1 after 12, 24, 36, and $48 \mathrm{~h}$ incubation. Results are expressed as means \pm SEM from three separate experiments. Means without a common letter denote significant differences according Least Significant Difference method ( $p<0.05$ ); SEM, standard error of the mean. a, b, c, d, indicate significant differences between treatments at the $5 \%$ level of probability $(p<0.05)$.

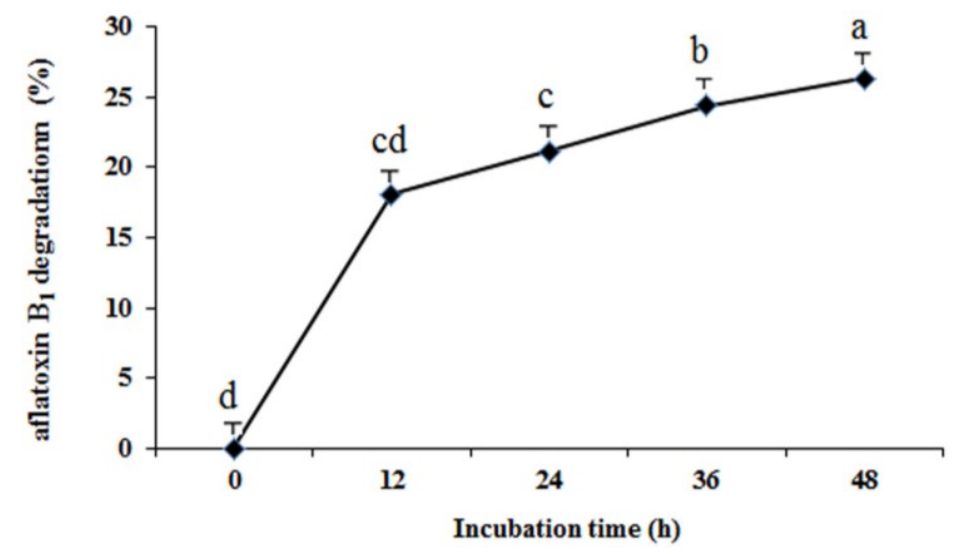




\subsection{Identification of Isolate $N D-1$}

ND-1 appeared on NA as round fluffy colonies. The conidia color of colonies was black and reverse color of the colonies was yellowish. The conidia shape shown by the strains was globose with smooth conidiophores. Moreover, the conidial head shape was globose and branching pattern was Bi-verticillate. As observed in an electrophoretic image of the PCR amplification product for 18S rDNA of the ND-1 strain, the product was a single band of 1600-1700 bp (Figure 2). The genetic sequence of PCR amplification product was obtained after sequencing. Determination of the 18S rDNA gene sequence using the BLAST Search tool in the GenBankDNA database revealed that the isolate belonged to the genus Aspergillus (Figure 3). The closest relationship (99.7\% sequence similarity) obtained with the described species was Aspergillus niger strain CS 1-1 (GenBank: HM590646.1). This indicated that ND-1 was a strain of Aspergillus niger. Aspergillus niger has been previously reported to degrade ochratoxin A [21] and zearalenone [22]. However, this is the first report that a fungus in this species exhibits a degradation function in aflatoxin $\mathrm{B}_{1}$. This finding provides a new solution for aflatoxin $\mathrm{B}_{1}$ degradation. However, optimization of fermentation conditions required further research.

Figure 2. Electrophoresis image of the PCR amplification products of $18 \mathrm{~S}$ rDNA of isolate ND-1.

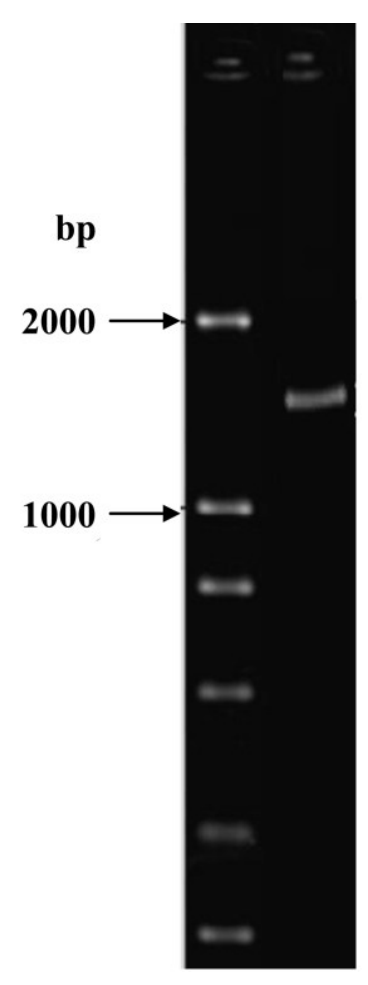


Figure 3. Phylogenetic tree based on the $18 \mathrm{~S}$ rDNA gene sequences of isolate ND-1 and related taxa.

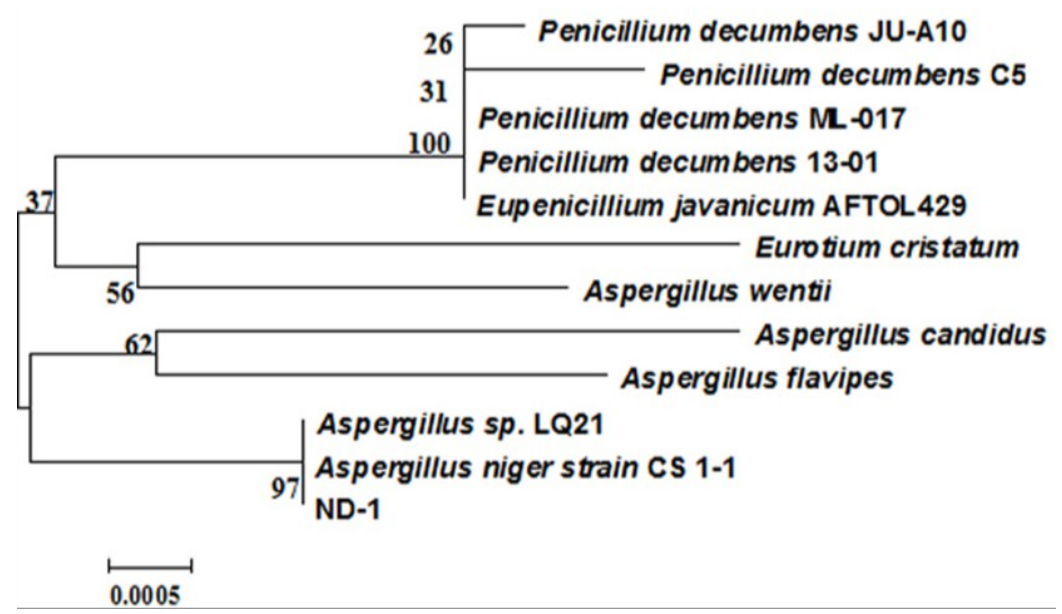

\subsection{Optimization of Fermentation Conditions for Aflatoxin $B_{1}$ Degradation}

When the carbon source was glucose, sucrose, maltose, mannitol, starch, lactose, and galactose, the relevant percentage of aflatoxin $\mathrm{B}_{1}$ degradation was 5.7\%, 8.5\%, 8.0\%, 4.9\%, 33.5\%, $14.9 \%$, and 11.1\%, respectively (Table 1). Starch was found to be the most suitable for aflatoxin $\mathrm{B}_{1}$ degradation. The degradation was significantly higher than other carbon sucrose. Moreover, it increased with the increased concentration of starch. Among the six different concentrations of starch tested, $4 \%$ was the best for aflatoxin $\mathrm{B}_{1}$ degradation (Table 1). Different carbon sources affect the growth of microorganisms. The growth of microorganisms was stimulated when the carbon source was utilizable [23]. When the carbon source was difficult to be utilized, the microorganism strains tended to utilize other carbon sources, which might promote a decrease in other carbon-based compounds [24]. Compared to monosaccharides and disaccharides, Aspergillus niger had difficulty using starch as a carbon source and selected aflatoxin $\mathrm{B}_{1}$ as the carbon source.

Table 1. Effect of different carbon sources and starch concentrations on aflatoxin $\mathrm{B}_{1}$ degradation (\%) by Aspergillus niger. The reactions were carried out at $32{ }^{\circ} \mathrm{C}$ with agitation at $200 \mathrm{rpm}$ for $24 \mathrm{~h}$. Sterile MTM was used to substitute microbial culture in the control. Results are expressed as means \pm SEM of three replicates. Means without a common letter denote significant differences according Least Significant Difference method $(p<0.01)$; SEM, standard error of the mean.

\begin{tabular}{cccc}
\hline Carbon sources & Aflatoxin B $_{\mathbf{1}}$ degradation (\%) & Concentrations of starch (\%) & Aflatoxin B degradation (\%) \\
\hline Starch & $33.5 \pm 1.5^{\mathrm{A}}$ & 4.0 & $35.0^{\mathrm{A}} \pm 2.5^{\mathrm{A}}$ \\
Lactose & $14.9 \pm 1.1^{\mathrm{B}}$ & 3.0 & $34.0^{\mathrm{A}} \pm 1.5^{\mathrm{A}}$ \\
Galactose & $11.1 \pm 1.6^{\mathrm{B}, \mathrm{C}}$ & 2.0 & $33.1 \pm 1.6^{\mathrm{A}}$ \\
Sucrose & $8.5 \pm 0.9^{\mathrm{B}, \mathrm{C}}$ & 1.0 & $19.5^{\mathrm{A}} \pm 2.2^{\mathrm{B}}$ \\
Maltose & $8.0 \pm 0.7^{\mathrm{B}, \mathrm{C}}$ & 0.5 & $14.0 \pm 0.5^{\mathrm{B}, \mathrm{C}}$ \\
Glucose & $5.74 \pm 0.4^{\mathrm{B}, \mathrm{C}}$ & 0.2 & $9.0 \pm 1.0^{\mathrm{C}}$ \\
Mannitol & $4.9 \pm 0.5^{\mathrm{C}}$ & - & - \\
\hline A, B, C, indicate significant differences between treatments at the 1\% level of probability $(p<0.01)$.
\end{tabular}


As shown in Table 2, when the nitrogen source was peptone, proteose peptone, beef extracts, tryptone, beef extract peptone, acidicase peptone, mixed ammonium salt and ammonium nitrate, the relevant percentage of aflatoxin $\mathrm{B}_{1}$ degradation was $33.1 \%, 45.1 \%, 32.6 \%, 50.7 \%, 33.3 \%, 47.0 \%$, $37.0 \%$ and $39.1 \%$, respectively. Tryptone was found to be the most suitable for aflatoxin $\mathrm{B}_{1}$ degradation. Among the five different concentrations of tryptone tested, $0.5 \%$ was the best for aflatoxin $\mathrm{B}_{1}$ degradation. Appropriate nitrogen source and concentration would not only stimulate the growth but also affect the expression of biosynthetic genes and therefore the production of microorganisms [24-26].

According to the orthogonal method, the effect of incubation temperature, period and amount of inoculum on aflatoxin $\mathrm{B}_{1}$ degradation was analyzed. The order of effects of all factors on aflatoxin $\mathrm{B}_{1}$ degradation was temperature $>$ amount of inoculum $>$ time $(\mathrm{A}>\mathrm{C}>\mathrm{B})$. In terms of the maximum $\mathrm{K}$-value of each column, optimal level of each factor for aflatoxin $\mathrm{B}_{1}$ degradation was A2B4C2, corresponding the optimal fermentation conditions included as follows: with the amount of inoculum of 3\%, inoculated cultures were incubated at $32{ }^{\circ} \mathrm{C}$ for $24 \mathrm{~h}$ in a shaker incubator. It has been reported previously that growth and enzyme production of microbes were affected by variations in incubation temperature, period and amount of inoculum [27-29].

The initial $\mathrm{pH}$ value in MTM showed a significant effect on aflatoxin $\mathrm{B}_{1}$ degradation (Table 2). The highest percentage of aflatoxin $\mathrm{B}_{1}$ degradation was obtained at $\mathrm{pH}$ of 6.0 . The $\mathrm{pH}$ of medium is a very important environmental factor, which is often neglected. Many investigators claimed that the different morphology of fungi mycelia under a different initial $\mathrm{pH}$ value was the critical factor in biomass accumulation and metabolite formation [30,31]. In the present study, the differences among percentage of aflatoxin $\mathrm{B}_{1}$ degradation at $\mathrm{pH}$ of $6.5-8$ were not significant.

Table 2. Effect of different nitrogen sources, tryptone concentrations and initial $\mathrm{pH}$ value on aflatoxin $\mathrm{B}_{1}$ degradation (\%) by Aspergillus niger. The reactions were carried out at $32{ }^{\circ} \mathrm{C}$ with agitation at $200 \mathrm{rpm}$ for $24 \mathrm{~h}$. Sterile MTM was used to substitute microbial culture in the control. Results are expressed as means \pm SEM of three replicates. In nitrogen sources group, means without a common letter denote significant differences according Least Significant Difference method ( $p<0.05$ ); in tryptone concentrations group and initial $\mathrm{pH}$ value group, means without a common letter denote significant differences according Least Significant Difference method $(p<0.01)$; SEM, standard error of the mean.

\begin{tabular}{|c|c|c|c|c|c|}
\hline Nitrogen sources & $\begin{array}{c}\text { Aflatoxin } \mathrm{B}_{1} \\
\text { degradation (\%) }\end{array}$ & $\begin{array}{l}\text { Concentrations } \\
\text { of tryptone (\%) }\end{array}$ & $\begin{array}{c}\text { Aflatoxin } B_{1} \\
\text { degradation (\%) }\end{array}$ & $\begin{array}{c}\text { Initial } \\
\text { pH value }\end{array}$ & $\begin{array}{c}\text { Aflatoxin } B_{1} \\
\text { degradation (\%) }\end{array}$ \\
\hline tryptone & $50.7 \pm 0.6^{\mathrm{a}}$ & 0.5 & $50.7 \pm 0.6^{\mathrm{A}}$ & 6.0 & $58.2 \pm 0.9^{\mathrm{A}}$ \\
\hline Acidicase peptone & $47.0 \pm 1.0^{b}$ & 0.7 & $50.4 \pm 0.4^{\mathrm{A}}$ & 6.5 & $50.7 \pm 0.6^{\mathrm{B}}$ \\
\hline Proteose peptone & $45.1 \pm 1.5^{b}$ & 0.9 & $49.8 \pm 0.3^{\mathrm{A}}$ & 7.0 & $49.2 \pm 1.0^{\mathrm{B}}$ \\
\hline Ammonium nitrate & $39.1 \pm 1.1^{\mathrm{c}}$ & 0.3 & $38.9 \pm 1.6^{\mathrm{B}}$ & 7.5 & $47.9 \pm 1.6^{\mathrm{B}}$ \\
\hline Mixed ammonium salt & $37.0 \pm 1.0^{\mathrm{c}}$ & 0.1 & $14.1 \pm 0.9^{\mathrm{C}}$ & 8.0 & $47.1 \pm 1.1^{\mathrm{B}}$ \\
\hline Beef extract peptone & $33.3 \pm 0.8^{\mathrm{d}}$ & - & - & 5.5 & $35.2 \pm 0.9^{\mathrm{C}}$ \\
\hline Peptone & $33.1 \pm 1.6^{\mathrm{d}}$ & - & - & 5.0 & $27.4 \pm 1.8^{\mathrm{D}}$ \\
\hline Beef extract & $32.6 \pm 1.1^{\mathrm{d}}$ & - & - & - & - \\
\hline
\end{tabular}




\subsection{Degradation of Aflatoxin $B_{1}$ by the Supernatant, Cells and Cell Extracts of ND-1}

The aflatoxin $\mathrm{B}_{1}$ degradation activity of ND-1 supernatant was significantly stronger than cells and cell extracts (Figure 4). The supernatant, cells and cell extracts of ND-1 could degrade 43.4\%, 5.9\%, and $0.8 \%$ aflatoxin $\mathrm{B}_{1}$, respectively. Some similar results were reported. Culture supernatant of Stenotrophomonas maltophilia was able to degrade $78.7 \%$ aflatoxin $\mathrm{B}_{1}$ after $72 \mathrm{~h}$ incubation [19]. The extracellular extracts of Rhodococcus erythropolis liquid culture could degrade $66.8 \%$ aflatoxin $\mathrm{B}_{1}$ after $72 \mathrm{~h}$ incubation [18]. In addition, the active ingredient in the culture supernatant was considered to be enzymatic [18].

Figure 4. Degradation of aflatoxin $\mathrm{B}_{1}$ by the supernatant, cells and cell extracts of Aspergillus niger after $24 \mathrm{~h}$ incubation. MTM was used to substitute supernatant in the control. The phosphate buffered saline was used to substitute cell and cell extracts in the control. Results are expressed as means \pm SEM from three separate experiments. Means without a common letter denote significant differences according Least Significant Difference method $(p<0.01)$; SEM, standard error of the mean. A, B, C, indicate significant differences between treatments at the $1 \%$ level of probability $(p<0.01)$.

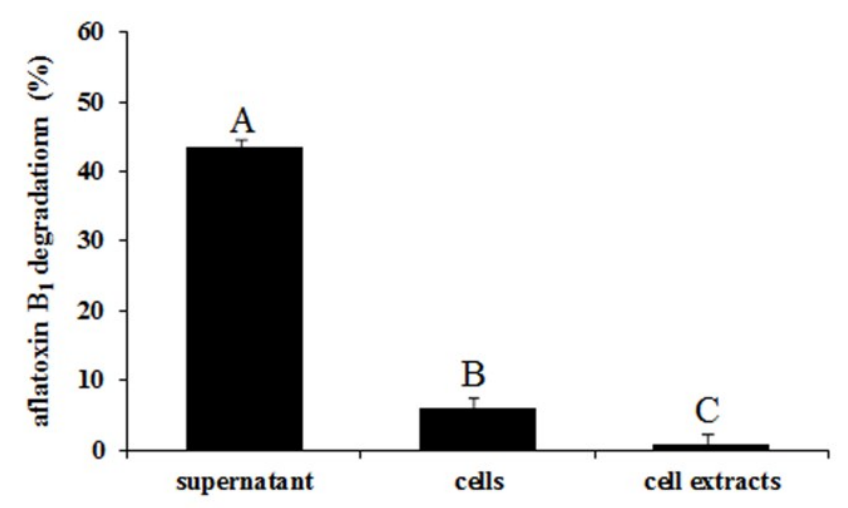

2.6. Effects of Heat Treatment, Temperature, $\mathrm{pH}$, and Metal Ions on Aflatoxin B ${ }_{1}$ Degradation by the Supernatant

The results showed that the percentage of aflatoxin $\mathrm{B}_{1}$ degradation decreased from $42.1 \%$ to $11.8 \%$ and $3.0 \%$ when the supernatant dipped at 50 and $60{ }^{\circ} \mathrm{C}$ for $6 \mathrm{~h}$, respectively (Figure 5). Heat treatment decreased the aflatoxin $\mathrm{B}_{1}$ degradation activities of culture supernatant. The higher the temperature was, the faster the activity decreased. Guan et al. reported that when culture supernatant was heated (boiling water bath for $10 \mathrm{~min}$ ), no degradation activity was observed [19]. 
Figure 5. Effect of heat treatment on aflatoxin $\mathrm{B}_{1}$ degradation by the supernatant of Aspergillus niger. The supernatant was dipped at 50 and $60^{\circ} \mathrm{C}$ for 2,4 , and $6 \mathrm{~h}$, respectively. Results are expressed as means \pm SEM from three separate experiments. Means without a common letter denote significant differences according Least Significant Difference method $(p<0.05)$; SEM, standard error of the mean. a, b, c, d, e, indicate significant differences between treatments at the $5 \%$ level of probability $(p<0.05)$.

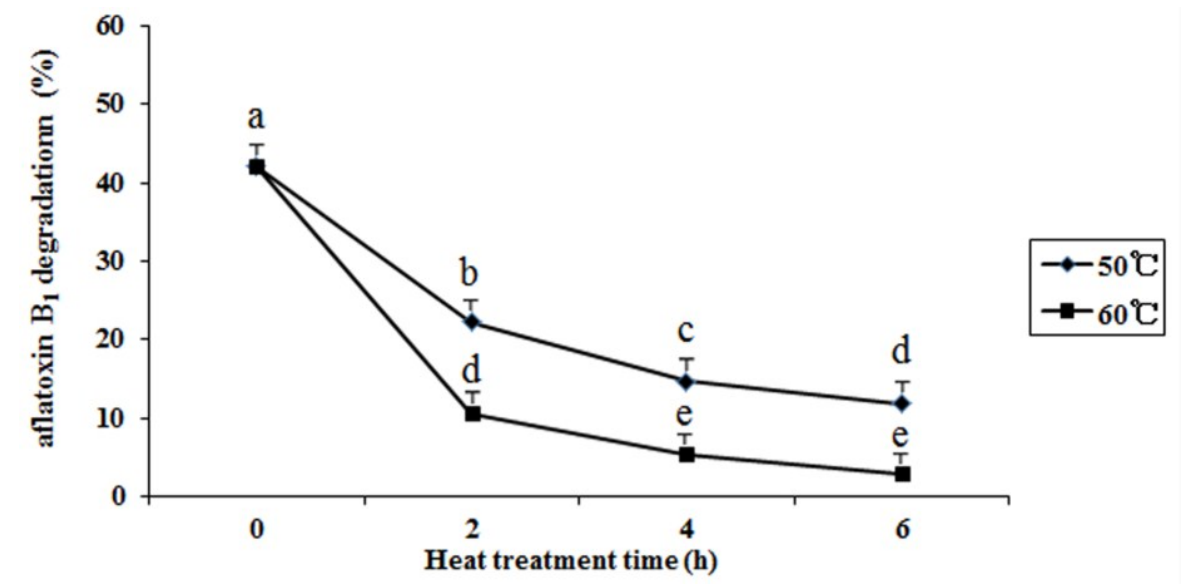

The effect of temperature on aflatoxin $\mathrm{B}_{1}$ degradation by the supernatant of ND-1 is shown in Figure 6 . The highest percentage of aflatoxin $\mathrm{B}_{1}$ degradation (42.1\%) was obtained at $35{ }^{\circ} \mathrm{C}$. The aflatoxin $\mathrm{B}_{1}$ degradation increased at first but later decreased as the temperature went up from 20 to $50{ }^{\circ} \mathrm{C}$. Temperature effect the growth of microorganisms, thus the metabolism production.

Figure 6. Effect of temperature on aflatoxin $\mathrm{B}_{1}$ degradation by the supernatant of Aspergillus niger. Results are expressed as means \pm SEM from three individual experiments. Means without a common letter denote significant differences according Least Significant Difference method ( $p<0.05$ ); SEM, standard error of the mean. a, b, c, d, e, indicate significant differences between treatments at the $5 \%$ level of probability $(p<0.05)$.

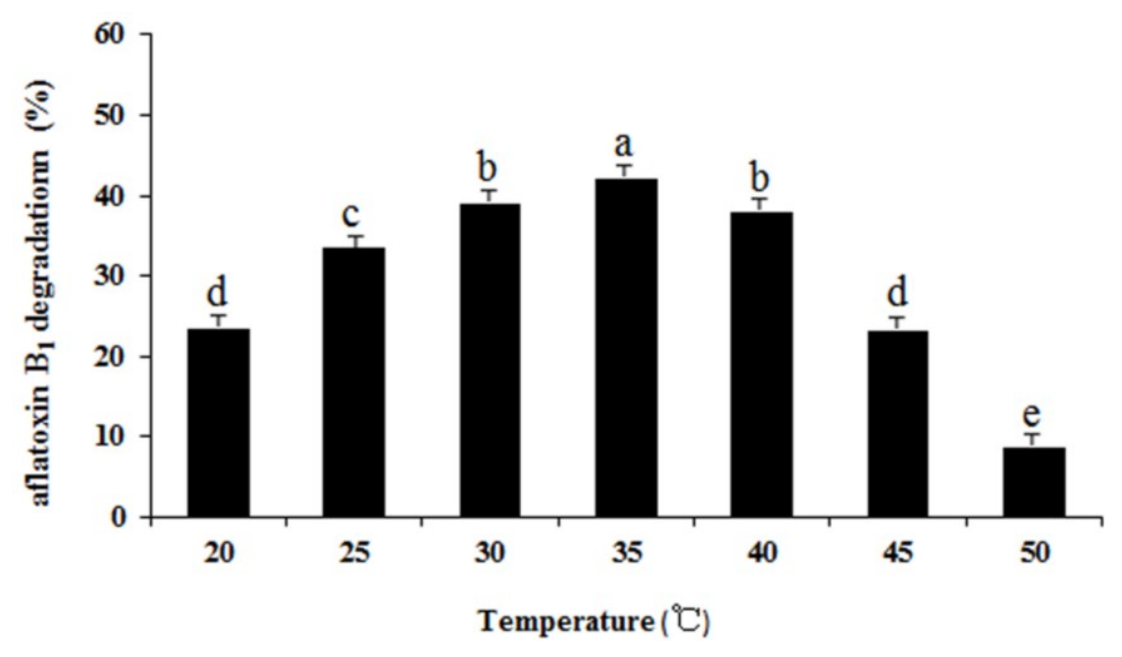

The highest percentage of aflatoxin $\mathrm{B}_{1}$ degradation (41.4\%) was obtained at $\mathrm{pH} 6.0$ and lowest (20.3\%) at $\mathrm{pH} 4.0$ (Figure 7). The correlation of aflatoxin $\mathrm{B}_{1}$ degradation with $\mathrm{pH}$ values is typical for enzymatic reactions. Enzymes have an optimal $\mathrm{pH}$ range for maximal activities. 
Figure 7. Effect $\mathrm{pH}$ on aflatoxin $\mathrm{B}_{1}$ degradation by the supernatant of Aspergillus niger. Results are expressed as means \pm SEM from three separate experiments. Means without a common letter denote significant differences according Least Significant Difference method $(p<0.05)$; SEM, standard error of the mean. a, b, c, d, indicate significant differences between treatments at the $5 \%$ level of probability $(p<0.05)$.

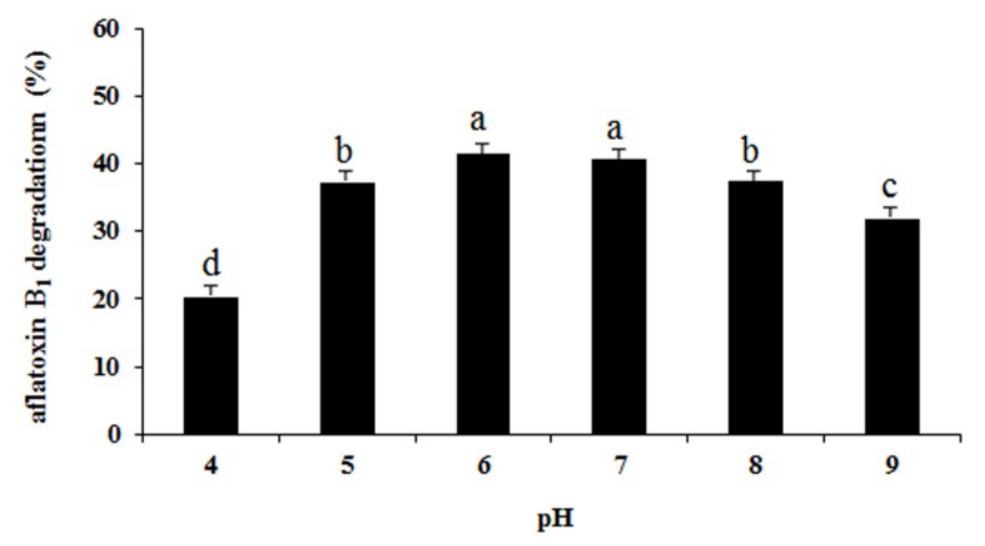

The effect of different metal ions on aflatoxin $\mathrm{B}_{1}$ degradation is shown in Figure 8. Compared to the treatment without ions (41.4\%), all metal ions decreased the percentage of aflatoxin $\mathrm{B}_{1}$ degradation. Ions $\mathrm{Pb}^{2+}$ showed the strongest inhibition function $(p<0.001)$. Similar results were reported that $\mathrm{Cu}^{2+}$, $\mathrm{Mn}^{2+}$ and $\mathrm{Zn}^{2+}$ inhibited aflatoxin $\mathrm{B}_{1}$ degradation by Flavobacterium aurantiacum [32]. But contrary to the results of our study, D'Souza and Brackett (2000) reported that incubating cells with 0.1, 1 and $10 \mathrm{mM} \mathrm{Ca}^{2+}$ for $48 \mathrm{~h}$ significantly increased aflatoxin $\mathrm{B}_{1}$ degradation by $11.8 \%, 13.5 \%$, and $14.0 \%$, respectively [33]. Likewise, incubation with $0.1,1$, and $10 \mathrm{mM} \mathrm{Mg}^{2+}$ for $48 \mathrm{~h}$ significantly increased aflatoxin $\mathrm{B}_{1}$ degradation by $13.8 \%, 13.3 \%$, and $13.1 \%$, respectively. The effects of metal ions on degradation activity further supported the enzyme involvement in aflatoxin $\mathrm{B}_{1}$ degradation by the isolate.

Figure 8. Effect of metal ions on aflatoxin $\mathrm{B}_{1}$ degradation by the supernatant of Aspergillus niger. The sterilized deionized water was added to the reaction mixture in treatment without ions. Results are expressed as means \pm SEM from three individual experiments. Means without a common letter denote significant differences according Least Significant Difference method ( $p<0.05$ ); SEM, standard error of the mean. a, b, c, d, e, f, g, indicate significant differences between treatments at the $5 \%$ level of probability $(p<0.05)$.

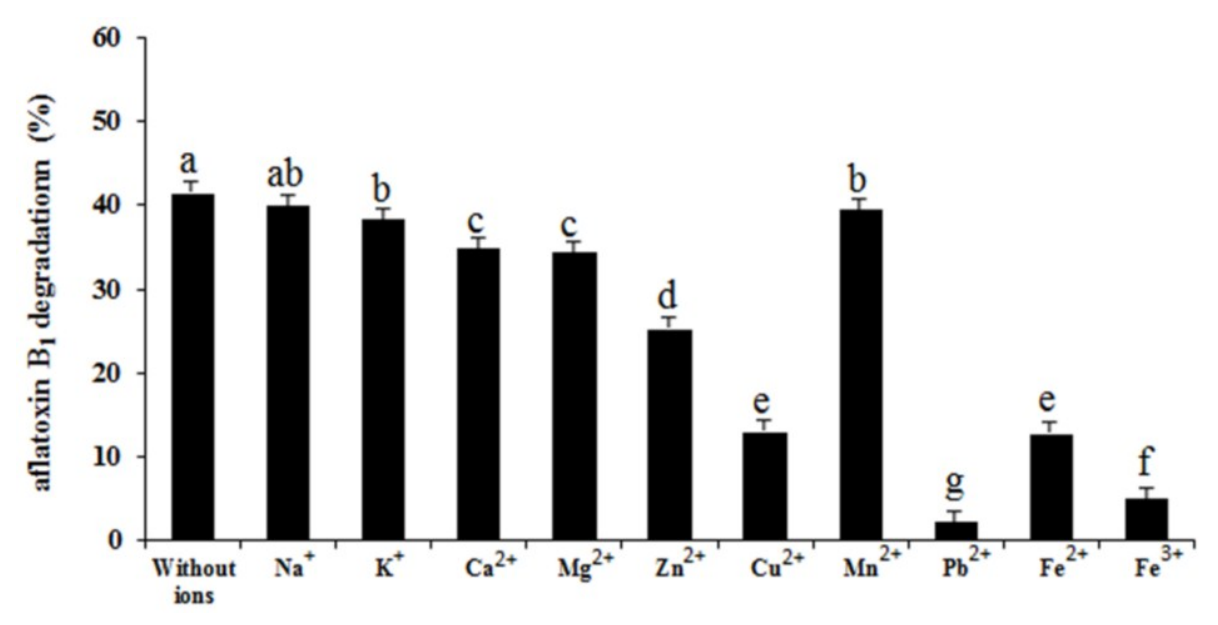




\section{Materials and Methods}

\subsection{Culture Media}

Each liter of coumarin medium (CM) contained $1.0 \mathrm{~g}$ coumarin (Aladdin, Shanghai, China), $2.0 \mathrm{~g}$ $\left(\mathrm{NH}_{4}\right)_{2} \mathrm{SO}_{4}, 0.2 \mathrm{~g} \mathrm{MgSO}_{4} \cdot 7 \mathrm{H}_{2} \mathrm{O}, 1.5 \mathrm{~g} \mathrm{Na}_{2} \mathrm{HPO}_{4} \cdot 12 \mathrm{H}_{2} \mathrm{O}, 0.001 \mathrm{~g} \mathrm{FeSO} \cdot 7 \mathrm{H}_{2} \mathrm{O}, 0.01 \mathrm{~g} \mathrm{CaCl}_{2} \cdot 2 \mathrm{H}_{2} \mathrm{O}$ and $1.5 \mathrm{~g} \mathrm{KH}_{2} \mathrm{PO}_{4}$. The $\mathrm{pH}$ of the medium was adjusted to 7.2. NB consisted of $3.0 \mathrm{~g}$ yeast extract, $5.0 \mathrm{~g}$ peptone, $6.0 \mathrm{~g}$ glucose, $10.0 \mathrm{~g} \mathrm{NaCl}$ per liter ( $\mathrm{pH} 7.0$ ). NA, which was NB plus $15 \mathrm{~g}$ agar, was used for preserving microbial isolates. Each liter of modified Thayer-Martin medium (MTM) contained $5.0 \mathrm{~g}$ peptone, $1.0 \mathrm{~g} \mathrm{~K}_{2} \mathrm{HPO}_{4}, 2.0 \mathrm{~g}$ yeast extract, $0.5 \mathrm{~g} \mathrm{MgSO}_{4}$ and $20.0 \mathrm{~g}$ glucose. The $\mathrm{pH}$ of the medium was adjusted to 6.4 .

\subsection{Isolation of Microorganisms}

One hundred and sixteen samples were selected for aflatoxin $\mathrm{B}_{1}$ degradation. The samples consisted of 16 corn, 12 distillers dried grains with solubles, 10 corn gluten meal, eight corn germ meal, 12 maize gluten feed, 16 wheat bran, 13 wheat germ meal, 14 soybean meal, and 15 types of meal collected from eight regions of Northeastern China where the feed ingredients might be affected by mycotoxin contamination.

Each pulverized sample $(2.0 \mathrm{~g})$ were dissolved in normal saline $(10 \mathrm{~mL})$, and then fully vortexed for $1 \mathrm{~min}$. Supernatant $(0.1 \mathrm{~mL})$ was transferred to NB $(10 \mathrm{~mL})$ medium, and cultured for $24 \mathrm{~h}$ at $37^{\circ} \mathrm{C}$. The microbe liquid $(0.2 \mathrm{~mL})$ was plated on plates of NA, which was incubated at $37{ }^{\circ} \mathrm{C}$ until visible colonies appeared. Single colonies were isolated and transferred to fresh NA for six times. Colonies were preserved as pure isolates on NA.

Screening microbes for aflatoxin $\mathrm{B}_{1}$ degradation was carried out in CM. After $72 \mathrm{~h}$ of culture at $32^{\circ} \mathrm{C}$, strains that could grow in CM were selected for rescreening. This procedure was repeated three times.

Rescreening microbes for aflatoxin $\mathrm{B}_{1}$ degradation was carried out following the $\mathrm{K}-\mathrm{B}$ disk diffusion method of CLSI-approved standard M02-A10 [34], with slight modifications. 0.01g aflatoxin $\mathrm{B}_{1}$ standard (Sigma, St. Louis, MO, USA) was dissolved in sterilized deionized water $(1000 \mathrm{~mL})$ to a stock solution of $10,000 \mathrm{ppb}$. Sterilized aflatoxin $\mathrm{B}_{1}$ solution $(0.4 \mathrm{~mL})$ was coated uniformly on NA. A 6-mm diameter sterilized filter paper dipped in each strains culture broth was carefully placed on top of the NA. After $24 \mathrm{~h}$ of incubation at $37^{\circ} \mathrm{C}$, the plates of NA were exposed to UV light irradiation to observe the change of fluorescent color. Strains that the fluorescence around them disappeared were selected and tested for aflatoxin $\mathrm{B}_{1}$ degradation.

\subsection{Determination of Aflatoxin $B_{1}$ Degradation}

The degradation of aflatoxin $\mathrm{B}_{1}$ by the selected strains was carried out in NB. Twelve-hour pre-inoculum $(2.4 \mathrm{~mL})$ was inoculated in NB $(77.6 \mathrm{~mL})$ containing aflatoxin $\mathrm{B}_{1}(10 \mathrm{ppb})$. Inoculated cultures were incubated at $32{ }^{\circ} \mathrm{C}$ with agitation at $200 \mathrm{rpm}$ for $0,12,24,36$, and $48 \mathrm{~h}$ in a shaker incubator (Harbin Donglian Electronic Equipment Inc., Harbin, China). After incubation, the cells were removed by centrifugation at 10,000 g for 5 min (Allegra 64R, Beckman Coulter Inc., Brea, CA, USA). Sterile NB was used to substitute microbial culture in the control. The resulting supernatant was used for aflatoxin $\mathrm{B}_{1}$ analysis. Sterile NB was used to substitute microbial culture in the control. 
The concentration of aflatoxin $\mathrm{B}_{1}$ in the culture medium was determined with an aflatoxin $\mathrm{B}_{1}$ test kit using the ELISA method (aflatoxin B1 FTRT, ELISA Technologies, Inc., Gainesville, FL, USA). The reaction mixtures were extracted with methanol $(80 \%)$ by mixing gently for 10 min at room temperature. The methanol extracts were evaporated under a mild stream of nitrogen at $50{ }^{\circ} \mathrm{C}$, the residue was dissolved in $2.0 \mathrm{~mL}$ of sample dilution buffer. $50 \mu \mathrm{L}$ aflatoxin $\mathrm{B}_{1}$ standard solutions and $50 \mu \mathrm{L}$ prepared test samples were added into separate wells of microtiter plate, in duplicate. Then, $25 \mu \mathrm{L}$ of conjugate (Aflatoxin-HRP) and $25 \mu \mathrm{L}$ of antibody solution were added to each well, mixed gently and incubated for $1 \mathrm{~h}$ in the dark at $37^{\circ} \mathrm{C}$. The liquid was then removed completely from the wells; the each well was washed with $250 \mu \mathrm{L}$ rinsing buffer. The washing procedure was repeated for three times. After the washing step, $100 \mu \mathrm{L}$ TMB substrate solution was added to each well and incubated for $30 \mathrm{~min}$ at room temperature $\left(20-25^{\circ} \mathrm{C}\right)$. Finally, $100 \mu \mathrm{L}$ of the stop solution was added to each well and the absorbance was measured at $450 \mathrm{~nm}$ in ELISA reader (TECAN Inc., Durham, NC, USA). The percentage of aflatoxin $\mathrm{B}_{1}$ degradation (D) was calculated using the following formula:

$$
D=\left[\left(X_{3}-X_{2}\right)-\left(X_{3}-X_{1}\right)\right] X_{3}^{-1} \times 100 \%=\left(X_{1}-X_{2}\right) X_{3}^{-1} \times 100 \%
$$

where:

$X_{I}$ : The concentration of aflatoxin $\mathrm{B}_{1}$ in the control after fermentation;

$X_{2}$ : The concentration of aflatoxin $\mathrm{B}_{1}$ in treatment after fermentation;

$X_{3}$ : The initial concentration of aflatoxin $\mathrm{B}_{1}$ before fermentation.

\subsection{Identification of the Aflatoxin B $B_{1}$ Degradation Strains}

The isolates were cultured for 7 days on NA at $37{ }^{\circ} \mathrm{C}$. Pigment production and the colony characteristics were noted. The conidia, hyphae, conidial head, conidiophores, spores, etc. were observed microscopically for morphological identification. DNA was extracted by using the GenEluteTM Kit (Bacterial Genomic DNA Kit, Sigma, St. Louis, MO, USA) according to the manufacturer's instructions. $18 \mathrm{~S}$ rDNA, was amplified by PCR using universal primers (5'-GTAGTCATATGCTTGTCTC-3'; 5'-TCCGCAGGTTCACCTACGGA-3') [35]. The amplified product was analyzed using $1.2 \%$ agarose gel electrophoresis. Purified DNA was sequenced by Invitrogen (Shanghai, China). The sequences were aligned with those in GenBank using the Blast program to determine the closest known relatives of the partial 18S rDNA gene sequences obtained. The generated DNA sequences and sequences derived from GenBank were aligned using the ClustalX program [36]. Neighbor joining analysis and calculation of bootstrap values were performed using the MEGA program.

\subsection{Optimization of Fermentation Conditions}

All optimization experiments were conducted in MTM. $12 \mathrm{~h}$ pre-inoculum $(2.4 \mathrm{~mL})$ was inoculated in MTM (77.6 mL) containing aflatoxin $\mathrm{B}_{1}(10 \mathrm{ppb})$. Inoculated cultures were incubated at $32{ }^{\circ} \mathrm{C}$ with agitation at $200 \mathrm{rpm}$ for $24 \mathrm{~h}$ in a shaker incubator. After incubation, the cells were removed by centrifugation at $10,000 \mathrm{~g}$ for $5 \mathrm{~min}$. The resulting supernatant was used for aflatoxin $\mathrm{B}_{1}$ analysis. Sterile MTM was used to substitute microbial culture in the control. The aflatoxin $\mathrm{B}_{1}$ degradation tests were performed as described in Section 3.3. 


\subsubsection{Optimization of Fermentation Medium}

For the carbon source tests, peptone was added as the nitrogen source during the tests. $20 \%$ glucose, sucrose, maltose, mannitol, starch, lactose, and galactose were individually introduced into MTM to determine the effect of the carbon source on aflatoxin $\mathrm{B}_{1}$ degradation.

The effect of different concentrations of the best carbon source on aflatoxin $\mathrm{B}_{1}$ degradation was studied in MTM with $0.2 \%, 0.5 \%, 1.0 \%, 2.0 \%, 3.0 \%$, and $4.0 \%$ of optimized carbon source.

For the nitrogen source tests, the optimized carbon source was added as the carbon source instead of glucose. $0.5 \%$ peptone, proteose peptone, beef extract, tryptone, beef extract peptone, acidicase peptone, mixed ammonium salt $\left(\mathrm{NH}_{4} \mathrm{NO}_{3}:\left(\mathrm{NH}_{4}\right)_{2} \mathrm{SO}_{4}=1: 1\right)$, and ammonium nitrate were individually introduced into the MD medium to determine the effect of the nitrogen source on aflatoxin $\mathrm{B}_{1}$ degradation.

The effect of different concentrations of the best nitrogen source on aflatoxin $\mathrm{B}_{1}$ degradation was studied in MTM with $0.1 \%, 0.3 \%, 0.5 \%, 0.7 \%$, and $0.9 \%$ of optimized nitrogen source.

\subsubsection{Optimization of Incubation Temperature, Period, Amount of Inoculum and pH}

The orthogonal $\mathrm{L}_{16}\left(4^{3}\right)$ was used to optimize incubation temperature, period and amount of inoculum. The levels of each factor are listed in Table 3.

In the $\mathrm{pH}$ tests, initial $\mathrm{pH}$ value in MTM was adjusted to 5.0, 5.5 and 6.0 by using $\mathrm{HCl}$, and to 6.5, 7.0, 7.5, and 8.0 by using $\mathrm{NaOH}$.

Table 3. Orthogonal optimization of different incubation temperature, period and amount of inoculum for the aflatoxin $\mathrm{B}_{1}$ degradation by ND-1. Sterile MTM was used to substitute microbial culture in the control.

\begin{tabular}{cccc}
\hline Factors & $\mathbf{A ~}\left({ }^{\circ} \mathbf{C}\right)$ & $\mathbf{B ~ ( h )}$ & $\mathbf{C ~ ( \% )}$ \\
\hline Level 1 & 28 & 12 & 1 \\
Level 2 & 32 & 24 & 3 \\
Level 3 & 36 & 36 & 5 \\
Level 4 & 40 & 48 & 7 \\
\hline
\end{tabular}

Symbols A, B and C represent factors of incubation temperature, period and amount of inoculum.

\subsection{Degradation of Aflatoxin B $B_{1}$ by the Supernatant, Cells and Cell Extracts of Strains}

Twelve-hour pre-inoculum $(2.4 \mathrm{~mL})$ was inoculated in MTM $(77.6 \mathrm{~mL})$ in a $100 \mathrm{~mL}$ flask. Inoculated cultures were incubated at $32{ }^{\circ} \mathrm{C}$ with agitation at $200 \mathrm{rpm}$ for $24 \mathrm{~h}$ in a shaker incubator. The preparation of supernatant, cell and cell extracts was carried out following the method of Teniola et al. [37]. The supernatant and cell were obtained by the following procedures. Cells were pelleted by centrifugation at $10,000 \mathrm{~g}$ for $5 \mathrm{~min}$. Cell pellets were washed twice with phosphate buffered saline (pH 7.4). The cell extracts were harvested by the following procedures. The cell pellets were resuspended in phosphate buffered saline ( $\mathrm{pH}$ 7.4) in preparation for cell rupture. The suspension was disintegrated thrice by using an ultrasonic cell disintegrator (Shanghai Xinzhi Instruments Inc., Shanghai, China). The cell disruption steps were carried out on ice. The disintegrated cell suspension was centrifuged at $12,000 \mathrm{~g}$ for $20 \mathrm{~min}$ at $4{ }^{\circ} \mathrm{C}$. Supernatant from the centrifugation step was filtered aseptically using sterile cellulose pyrogen free disposable filters of $0.2 \mu \mathrm{m}$ pore size. Aflatoxin $\mathrm{B}_{1}$ stock solution was added to each reaction liquid 
to reach a final concentration of $10 \mathrm{ppb}$. The degradation tests were carried out after incubation at $32{ }^{\circ} \mathrm{C}$ with agitation at $200 \mathrm{rpm}$ for $24 \mathrm{~h}$ in a shaker incubator as described in 3.3. MTM was used to substitute supernatant in the control. The phosphate buffered saline was used to substitute cell and cell extracts in the control.

\subsection{Effects of Heat Treatment, Temperature, $p H$ and Metal Ions on Aflatoxin B ${ }_{1}$ Degradation by the Supernatant}

The aflatoxin $\mathrm{B}_{1}$ degradation tests by the supernatant were performed as described in 3.6. MTM was used to substitute supernatant under the following conditions in the control.

The effect of heat treatment was determined by dipping the supernatant at 50 and $60{ }^{\circ} \mathrm{C}$ for 2,4 , and $6 \mathrm{~h}$, respectively.

To measure the effect of temperatures, the reaction mixture was incubated at $20,25,30,35,40,45$, and $50{ }^{\circ} \mathrm{C}$ with agitation at $200 \mathrm{rpm}$ for $24 \mathrm{~h}$ in a shaker incubator.

In the $\mathrm{pH}$ tests, initial $\mathrm{pH}$ value was adjusted to $4.0,5.0$ and 6.0 by using $\mathrm{HCl}$, and to 7.0, 8.0, and 9.0 by using $\mathrm{NaOH}$. The reaction mixture was incubated at $32{ }^{\circ} \mathrm{C}$ with agitation at $200 \mathrm{rpm}$ for $24 \mathrm{~h}$ in a shaker incubator.

To evaluate the effect of different metal ions, $\mathrm{Li}^{+}, \mathrm{Na}^{+}, \mathrm{K}^{+}, \mathrm{Ca}^{2+}, \mathrm{Mg}^{2+}, \mathrm{Zn}^{2+}, \mathrm{Cu}^{2+}, \mathrm{Mn}^{2+}, \mathrm{Pb}^{2+}, \mathrm{Fe}^{2+}$ and $\mathrm{Fe}^{3+}$ (in the form of $\mathrm{LiCl}, \mathrm{NaCl}, \mathrm{KCl}, \mathrm{CaCl}_{2}, \mathrm{MgSO}_{4}, \mathrm{ZnCl}_{2}, \mathrm{CuSO}_{4}, \mathrm{MnCl}_{2}, \mathrm{~Pb}\left(\mathrm{NO}_{3}\right)_{2}, \mathrm{FeSO}_{4}$, and $\mathrm{FeCl}_{3}$ ) was adding to the reaction mixture respectively in a final concentration of $5 \mathrm{mM}$. The sterilized deionized water was added to the reaction mixture in treatment without ions. The reaction mixture was incubated at $32{ }^{\circ} \mathrm{C}$ with agitation at $200 \mathrm{rpm}$ for $24 \mathrm{~h}$ in a shaker incubator.

\subsection{Statistical Analysis}

All specific experiments were repeated three times. Statistical analysis was performed using Statistix 8.1 (Analytical Software, Tallahassee, FL, USA, 2005). Analysis of variance (ANOVA) was performed to detected significance. Significant differences between means were determined using the Least Significant Difference method.

\section{Conclusions}

We employed a method using coumarin as a selective agent to search for aflatoxin $\mathrm{B}_{1}$ degradation microorganisms in this study. A strain of Aspergillus niger that could degrade $26.3 \%$ of aflatoxin $\mathrm{B}_{1}$ after $48 \mathrm{~h}$ of fermentation in NB was obtained. The degradation rose to $58.2 \%$ under the optimal fermentation conditions. The aflatoxin $\mathrm{B}_{1}$ degradation activity of Aspergillus niger culture supernatant was significantly stronger than cells and cell extracts and affected by heat treatment, temperature, $\mathrm{pH}$, and metal ions. The results indicated that the aflatoxin $\mathrm{B}_{1}$ degradation of Aspergillus niger is enzymatic and this process mainly occurs in the extracellular environment.

\section{Supplementary Materials}

Supplementary materials can be accessed at: http://www.mdpi.com/2072-6651/6/11/3157/s1. 


\section{Acknowledgments}

We gratefully acknowledge the financial support from the National Natural Science Foundation of China (No. 31272453, 31472104) and the China Agriculture Research System (CARS-36).

\section{Author Contributions}

Wei Zhang and Beibei Xue performed the experiments and wrote the manuscript. Mengmeng Li, Yang $\mathrm{Mu}$ and Zhihui Chen helped to analyze the data and prepared the figures. Jianping Li and Anshan Shan conceived and designed the experiments and modified the final edition of the manuscript.

\section{Conflicts of Interest}

The authors declare no conflict of interest.

\section{References}

1. Diener, U.L.; Cole, R.J.; Sanders, T.H.; Payne, G.A.; Lee, L.S.; Klich, M.A. Epidemiology of aflatoxin formation by Aspergillus flavus. Annu. Rev. Phytopathol. 1987, 25, 240-270.

2. Leontopoulos, D.; Siafaka, A.; Markaki, P. Black olives as substrate for Aspergillus parasiticus growth and aflatoxin B1 production. Food Microbiol. 2003, 20, 119-126.

3. Ito, Y.; Peterson, S.W.; Wicklow, D.T.; Goto, T. Aspergillus pseudotamarii, a new aflatoxin-producing species in Aspergillus section Flavi. Mycol. Res. 2001, 105, 233-239.

4. Peterson, S.W.; Ito, Y.; Horn, B.W.; Goto, T. Aspergillus bombycis, a new aflatoxigenic species and genetic variation in its sibling species, A. nomius. Mycologia 2001, 93, 689-703.

5. Kurtzman, C.P.; Horn, B.W.; Hesseltine, C.W. Aspergillus nomius, a new aflatoxin-producing species related to Aspergillus flavus and Aspergillus tamari. Antonie Van Leeuwenhoek 1987, 53, 147-158.

6. Richard, J.L.; Payne, G.A.; Desjardins, A.E. Mycotoxins: Risks in plant, animal and human systems. CAST Task Force Rep. 2003, 139, 101-103.

7. Hussein, S.H.; Brasel, J.M. Toxicity, metabolism, and impact of mycotoxins on humans and animals. Toxicology 2001, 167, 101-134.

8. Méndez-Albores, A.; Arámbula-Villa, G.; Loarca-Piña, M.G.F.; Castaño-Tostado, E.; Moreno-Martínez, E. Safety and efficacy evaluation of aqueous citric acid to degrade B-aflatoxins in maize. Food Chem. Toxicol. 2005, 43, 233-238.

9. Gowda, N.K.S.; Suganthi, R.U.; Malathi, V.; Raghavendra, A. Efficacy of heat treatment and sun drying of aflatoxin-contaminated feed for reducing the harmful biological effects in sheep. Anim. Feed Sci. Technol. 2007, 133, 167-175.

10. Basappa, S.C.; Shantha, T. Methods for detoxification of Aflatoxins in foods and feeds-A critical appraisal. J. Food Sci. Technol. 1996, 33, 95-107.

11. Henry, S.H.; Bosch, F.X.; Troxell, T.C. Reducing liver cancer-Global control of aflatoxin. Science 1999, 286, 2453-2454. 
12. Guengerich, F.P.; Johnson, W.W.; Ueng, Y.F.; Yamazaki, H.; Shimada, T. Involvement of cytochrome P450, glutathione S-transferase, and epoxide hydrolase in the metabolism of aflatoxin B1 and relevance to risk of human liver cancer. Environ. Health Perspect. 1996, 104, 557-562.

13. Laciaková, A.; Ciconova, P.; Máté, D.; Laciak, V. Aflatoxins and possibilities for their biological detoxification. Med. Weter 2008, 64, 276-279.

14. Farzaneh, M.; Shi, Z.Q.; Ghassempour, A.; Sedaghat, N.; Ahmadzadeh, M.; Mirabolfathy, M.; Javan-Nikkhah, M. Aflatoxin B1 degradation by Bacillus subtilis UTBSP1 isolated from pistachio nuts of Iran. Food Control 2012, 23, 100-106.

15. Khanafari, A.; Soudi, H.; Miraboulfathi, M.; Osboo, R.K. An in vitro investigation of Aflatoxin $B_{1}$ biological control by Lactobacillus plantarum. J. Biol. Sci. 2007, 4, 2553-2556.

16. Cao, H.; Liu, D.L.; Mo, X.M.; Xie, C.F.; Yao, D.S. A fungal enzyme with the ability of aflatoxin $\mathrm{B}_{1}$ conversion: Purification and ESI-MS/MS identification. Microbiol. Res. 2011, 166, 475-483.

17. Hormisch, D.; Brost, I.; Kohring, G.W.; Giffhorn, F.; Kroppensted, R.M.; Stackebrandt, E.; Farber, P.; Holzapfel, W.H. Mycobacterium fluoranthenivorans sp. nov., a fluoranthene and aflatoxin $\mathrm{B}_{1}$ degrading bacterium from contaminated soil of a former coal gas plant. J. Appl. Microbiol. 2004, 27, 653-660.

18. Alberts, J.F.; Engelbrecht, Y.; Steyn, P.S.; Holzapfel, W.H.; Vanzyl, W.H. Biological degradation of aflatoxin B1 by Rhodococcus erythropolis cultures. Int. J. Food Microbiol. 2006, 109, 121-126.

19. Guan, S.; Ji, C.; Zhou, T.; Li, J.; Ma, Q.; Niu, T. Aflatoxin B1 degradation by Stenotrophomonas maltophilia and other microbes selected using coumarin medium. Int. J. Mol. Sci. 2008, 9, 1489-1503.

20. Samuel, M.S.; Sivaramakrishna, A.; Mehta, A. Degradation and detoxification of aflatoxin B1 by Pseudomonas putida. Int. Biodeterior. Biodegrad. 2014, 86, 202-209.

21. Abrunhosa, L.; Santos, L.; Venâncio, A. Degradation of ochratoxin A by proteases and by a crude enzyme of Aspergillus niger. Food Biotechnol. 2006, 20, 231-242.

22. Sun, X.; He, X.; Li, Y.; Xu, D.; Qian, H. Biological detoxification of zearalenone by Aspergillus niger strain FS10. Food Chem. Toxicol. 2014, 72, 76-82.

23. Jonathan, S.G.; Fasidi, I.O. Effect of carbon, nitrogen and mineral sources on growth of Psathyerella atroumbonata (Pegler), a Nigerian edible mushroom. Food Chem. 2001, 72, 479-483.

24. Brzonkalik, K.; Herrling, T.; Syldatk, C.; Neumann, A. The influence of different nitrogen and carbon sources on mycotoxin production in Alternaria alternate. Int. J. Food Microbiol. 2011, 147, 120-126.

25. Nancib, A.; Nancib, N.; Meziane-Cherif, D.; Boubendir, A.; Fick, M.; Boudrant, J. Joint effect of nitrogen sources and $\mathrm{B}$ vitamin supplementation of date juice on lactic acid production by Lactobacillus casei subsp. Rhamnosus. Bioresour. Technol. 2005, 96, 63-67.

26. Kohut, G.; Ádám, A.L.; Fazekas, B.; Hornok, L. N-starvation stress induced FUM gene expression and fumonisin production is mediated via the HOG-type MAPK pathway in Fusarium proliferatum. Int. J. Food microbiol. 2009, 130, 65-69.

27. Sohail, M.; Siddiqi, R.; Ahmad, A.; Khan, S.A. Cellulase production from Aspergillus niger MS82: Effect of temperature and pH. New Biotechnol. 2009, 25, 437-441. 
28. Sharma, A.; Vivekanand, V.; Singh, R.P. Solid-state fermentation for gluconic acid production from sugarcane molasses by Aspergillus niger ARNU-4 employing tea waste as the novel solid support. Bioresour. Technol. 2008, 99, 3444-3450.

29. Sabu, A.; Augur, C.; Swati, C.; Pandey, A. Tannase production by Lactobacillus sp. ASR-S1 under solid-state fermentation. Process Biochem. 2006, 41, 575-580.

30. Shu, C.H.; Lung, M.Y. Effect of $\mathrm{pH}$ on the production and molecular weight distribution of exopolysaccharide by Antrodia camphorate in batch cultures. Process Biochem. 2004, 39, 931-937.

31. Wang, Y.; McNeil, B. pH effects on exopolysaccharide and oxalic acid production in cultures of Sclerotium glucanicum. Enzym. Microb. Technol. 1995, 17, 124-130.

32. D'Souza, D.H.; Brackett, R.E. The role of trace metal ions in aflatoxin $\mathrm{B}_{1}$ degradation by Flavobacterium aurantiacum. J. Food Prot. 1998, 61, 1666-1669.

33. D'Souza, D.H.; Brackett, R.E. The influence of divalent cations and chelators on aflatoxin $\mathrm{B}_{1}$ degradation by Flavobacterium aurantiacum. J. Food Prot. 2000, 63, 102-105.

34. Clinical and Laboratory Standards Institute (CLSI). Performance standards for antimicrobial disk susceptibility tests; Approved Standard-Tenth Edition (M02-A10); CLSI: Wayne, PA, USA, 2009.

35. Sivakumaran, S.; Bridge, P.; Roberts, P. Genetic relatedness among Filobasidiella species. Mycopathologia 2002, 156, 157-162.

36. Thompson, J.D.; Gibson, T.J.; Plewniak, F.; Jeanmougin, F.; Higgins, D.G. The CLUSTAL_X windows interface: Flexible strategies for multiple sequence alignment aided by quality analysis tools. Nucleic Acids Res. 1997, 25, 4876-4882.

37. Teniola, O.D.; Addo, P.A.; Brost, I.M.; Färber, P.; Jany, K.D.; Alberts, J.F.; van Zyi, W.H.; Steyn, P.S.; Holzapfel, W.H. Degradation of aflatoxin $\mathrm{B}_{1}$ by cell-free extracts of Rhodococcus erythropolis and Mycobacterium fluoranthenivorans sp. nov. DSM44556 ${ }^{\mathrm{T}}$. Int. J. Food Microbiol. 2005, 105, 111-117.

(C) 2014 by the authors; licensee MDPI, Basel, Switzerland. This article is an open access article distributed under the terms and conditions of the Creative Commons Attribution license (http://creativecommons.org/licenses/by/4.0/). 